\title{
LA DESCORTESÍA EN LA CORTESÍA: UNA REVISIÓN DEL ACTO DE HABLA DE LA INVITACIÓN DESDE LA PERSPECTIVA DEL EGOCENTRISMO
}

\author{
THE COURTESY IN THE DISCOURTESY: A REVIEW OF THE SPEAKING ACT \\ OF THE INVITATION FROM THE EGOCENTRISM PERSPECTIVE **
}

\section{Mariana Cortés Kandler*}

\begin{abstract}
RESUMEN
En este trabajo se analizan las invitaciones desde una perspectiva del egocentrismo, según la cual todos los actos se realizan en beneficio propio. Para definir este beneficio, se trabajó con el concepto de face entendido dentro de la teoría de la cortesía verbal de Brown y Levinson (1987). El objetivo de esta investigación es determinar hasta qué punto el acto de invitar es un acto cortés y porqué. Se realizaron diez entrevistas con el fin dilucidar los rasgos de cortesía (o descortesía) relacionados con el acto de invitar, y las respuestas se contrastaron con los resultados de Ferrer y Sánchez Lanza (2000), sobre el acto comisivo de invitar en el ámbito argentino, y el de Gil (2005), sobre las amenazas e invasiones a la imagen de los distintos actos de habla. Finalmente, se ofrece una caracterización de este acto prototípicamente cortés a partir de la muestra recolectada, y según las máximas de cortesía propuestas por Lakoff (1973).
\end{abstract}

Palabras clave: pragmática, cortesía verbal, amenazas a la imagen, invitaciones, revisión de acto de habla.

\section{ABSTRACT}

This paper seeks to evaluate invitations from an egocentric approach, according to which all actions ultimately search the benefit of the self. The concept of face, as it is understood within the theory of verbal politeness (Brown \& Levinson 1987), was used as an indicator. The purpose of this paper is to determine if and why the act of inviting is or could be considered a polite act. Ten interviews were carried out aiming to elucidate the features of courtesy (or discourtesy) of the act of inviting. The answers were contrasted with the proposals of Ferrer \& Sánchez Lanza (2000), which deals with the commissive act of invitation within the Argentinean domain, and Gil (2005), which presents the face threats toward both the speaker and the addressee, carried by the different speech acts. Finally, a characterization of this prototypically polite speech act is offered based on the sample gathered, and according to Lakoff's (1973) politeness maxims.

Key Words: pragmatics, politeness, threatens to the face, invitations, revision of speech act.

* $\quad$ Estudiante de Maestría, Universidad de Costa Rica.

** Traducción: Lic. Geannette Soto. Escuela de Lenguas Modernas, Universidad de Costa Rica.

Correo electrónico: mari.ckandler@gmail.com

Recepción: 02/04/13. Aceptación: 20/05/13. 
Pasamos casi todo el tiempo no como somos en realidad, sino disfrazados, para acomodarnos a nuestras profesiones o para aparentar que somos la persona que nuestros amigos, los parientes o las esposas esperan que seamos. O para aparentar ser lo que quisiéramos ser. Esto último es lo importante, porque cuando nos disfrazamos como queremos ser, lo hacemos para esconder lo que pensamos que somos. (1991: 14) Mesas reservadas Eric Kraft

\section{Introducción}

Vivimos en sociedad y todos los días tenemos que relacionarnos con otras personas, con otros egos, que son tan egos como nosotros mismos. Pero vivir en una comunidad implica también asumir toda una serie de normas sociales que regulan estas relaciones, y no acatar estas normas puede resultar en el asilamiento o en el castigo. La cortesía verbal se ha propuesto como uno de los mecanismos tanto para evitar los conflictos interpersonales (Brown y Levinson, 1987), como para mejorar las relaciones entre los miembros de una comunidad socio-cultural (Hernández-Flores, 2004; Barros García, 2010). Sin embargo, que un acto de habla se considere cortés depende en última instancia de la situación comunicativa: "la cortesía no es propia de determinadas clases de oraciones, sino de locuciones emitidas en una situación comunicativa específica" (Haverkate, 1994: 38).

La motivación para realizar este trabajo surge de la definición que ofrece Haverkate (1994) de las invitaciones:

Según su objeto ilocutivo, orientado hacia el beneficio del interlocutor, los actos comisivos se califican como actos prototípicos para comunicar cortesía positiva. Sin embargo, en el caso de las invitaciones, el patrón interaccional es bastante complejo debido al hecho paradójico de que el interlocutor que acepta una invitación no sólo se ve beneficiado, sino también amenazado por la misma. La amenaza está en que, al aceptar la invitación, el invitado corre el riesgo de dar la impresión de pensar solamente en su propio provecho. Por esta razón, se da por hecho que contrae una deuda con quien invita, que le obliga, en principio, a restablecer el equilibrio del balance coste-beneficio correspondiendo a la invitación cuando se dé la oportunidad. Al mismo tiempo, al que acepta la invitación se le impone la obligación social de reducir en lo posible el coste del que le invita. [...] Todo esto conlleva que no sólo sea cortés invitar, sino también rechazar la invitación. (Haverkate, 2004: 108-109, el destacado es mío).

De esta definición, surgieron varias dudas: ¿Es cortés realizar una invitación? ¿Es cortés rechazarla? ¿En qué situaciones? ¿Cómo amenaza el acto de invitar a las imágenes del hablante y del interlocutor? ¿En beneficio de quién se realizan las invitaciones? Para ilustrar, se ofrece un ejemplo de una de las entrevistas realizadas:

\section{$95 \mathrm{E}^{\mathrm{i}}$ : ¿te parece cortés / realizar una invitación?}

96 H3: /// depende porque si si hay que gente que le puede / más bien molestar ¿no? entonces uno tiene que analizar ese punto antes

$\mathrm{Si}$ se parte desde una perspectiva egocentrista, ningún acto es realmente desinteresado, pero entonces, ¿dónde radicaría la cortesía de este acto "prototípicamente cortés"? El objetivo de este trabajo es responder a esta y a las preguntas presentadas anteriormente dentro del marco del egocentrismo y el trabajo de imagen propuesto por Brown y Levinson (1987). Por último, las máximas de cortesía de Lakoff (1973) servirán como base para una revalorización del carácter cortés de las invitaciones. 


\section{Propuestas teóricas para el estudio de la cortesía en la interacción verbal}

El presente análisis del acto de habla de invitar parte de la idea que toda acción realizada por un individuo busca en alguna manera resultar en beneficio propio. Esto no quiere decir que se realice en detrimento de la otra persona, sino que, incluso cuando se beneficia al otro, se espera recibir algo a cambio por ese esfuerzo o energía invertidos. A este respecto, dice HaskiLeventhal (2009): "According to the egocentric approach, every altruistic act is done for future benefits or cooperation, and what motivates a person to help another are the tangible and perceived benefits she or he may gain, directly or indirectly" (2009: 273).

Esta autora agrega que "la compasión, el deseo de ayudar a los otros y el sacrificio son considerados como medios para mejorar la auto-imagen y la aprobación social" (HaskiLeventhal, 2009: 273, traducción libre). De igual manera, el altruismo resulta no de un deseo por hacer un acto en beneficio de otro, sino de la creencia de que este comportamiento trae un beneficio social o personal, y que si no se realiza, el individuo podría ser castigado. En esta misma línea, Haski-Leventhal cita a Batson (1991), quien dice: "Freud (1856-1939) perceived altruism as acting for one's own well-being. Even if altruistic motivation could develop, it is only a strategic expression of a more fundamental and egoistic one" (2009: 274).

Como señala Escandell Vidal (1996), las comunidades socioculturales se rigen por unas normas de comportamiento, entre las cuales están incluidas las normas de interacción lingüística. De esta manera, se favorecen ciertas formas de conducta y se sancionan otras; es decir, la comunidad clasifica ciertos comportamientos como corteses o descorteses o incluso como insultantes. Esta es una forma de cortesía codificada, es decir, son normas sociales que se conocen y que la sociedad espera que se cumplan; de lo contrario, la persona podría ser sancionada. Siguiendo la perspectiva egocentrista, los miembros de una sociedad aprenderían a acatar estas reglas y a hacer cosas por las otras personas porque saben que, de una manera u otra, redundará en beneficio propio.

Dentro de este contexto, Barros García (2010) se refiere al respecto: "Las invitaciones son uno de los recursos prototípicos de los que dispone el hablante para la expresión de cortesía valorizadora: están dirigidas hacia el oyente, pero repercuten en la imagen de afiliación de emisor y receptor, pues el primero será visto como una persona amable, educada y solidarizada con el otro, mientras que al receptor se le manifiesta afecto y se le reconoce su pertenencia al grupo" (p. 6). Este aspecto de afiliación, es decir, de pertenencia a un grupo, se tomará en cuenta para definir la invitación como un medio para mantener y reforzar las relaciones interpersonales.

Siguiendo a Escandell Vidal (1996), la cortesía también puede analizarse desde una perspectiva orientada más hacia la pragmalingüística. Así, la cortesía se entiende no como una norma social que la sociedad espera, sino como un conjunto de estrategias conversacionales destinadas a evitar tensiones y mantener una relación armónica entre los participantes. Para este trabajo, se tomarán en cuenta las estrategias que utilizan los informantes para realizar el acto de invitar, en relación con las amenazas a la imagen que este podría implicar.

Lakoff (1973) reconoce los conflictos que podrían surgir en las relaciones interpersonales y analiza los principios que regulan la interacción. Propone dos reglas básicas para la comunicación: sea claro, y sea cortés. La primera regla se apega al principio de cooperación de Grice, y la segunda hace alusión al carácter interpersonal de la interacción verbal. La autora entiende la cortesía como "un mecanismo que intenta reducir las tensiones creadas en la interacción" (Escandell Vidal, 1996, p. 142). Esta regla, además, se divide en tres estrategias o máximas: no imponga su voluntad, ofrezca opciones, y haga que el interlocutor se sienta bien reforzando los lazos de camaradería. 
De acuerdo con Haverkate (1994), la primera máxima, no imponga su voluntad, se refiere a situaciones en que la distancia social entre los interlocutores es grande, o no tienen mucha familiaridad. La segunda, ofrezca opciones, se utiliza en casos en que existe un equilibrio social, pero no hay mucha familiaridad. Ambas sirven para que el interlocutor no se sienta amenazado por el acto que el hablante realiza. La última, es de carácter más general, y se emplea para colocar al interlocutor en una posición agradable. Se emplea cuando la relación es cercana, o precisamente para estrechar la relación. Las primeras dos expresan cortesía negativa, y resultarán de principal importancia para este trabajo porque, de acuerdo con la muestra recolectada, es según estas máximas que se define el carácter cortés de las invitaciones, y no según el beneficio hacia el interlocutor, como se ha propuesto tradicionalmente.

Posteriormente dentro del estudio de la cortesía, Leech (1983) propone un principio de cortesía que, como el principio de cooperación de Grice, se desglosa en máximas, y pretende ser complementario de este. Las seis máximas en las que se divide son: la de tacto, generosidad, aprobación, modestia, acuerdo y simpatía; no todas se utilizan de igual manera para todos los actos. De acuerdo con el principio de cortesía, los interlocutores deben seleccionar las formas según su objetivo; es decir, dependiendo de si quieren mantener el equilibrio que existe entre ellos, o cambiarlo (para estrechar o distanciar la relación). En este sentido, las invitaciones resultan relevantes como manifestación de cortesía porque sirven para estrechar los lazos sociales. Por otra parte, Leech menciona que el principio de la cortesía es el que explica y justifica el uso de formas indirectas, que se restringe casi exclusivamente a los actos inherentemente descorteses. Este punto se discutirá más adelante.

Brown y Levinson (1987) profundizan en el tema de la cortesía y proponen una teoría que es considerada una de las propuestas más influyentes que intentan explicar el funcionamiento de la cortesía verbal. No se presenta como un sustituto de los principios conversacionales de Grice, sino como un complemento del aspecto interpersonal que no estaba contemplado en ese modelo (Escandell Vidal, 1996). Brown y Levinson parten de la idea que las sociedades tienen que controlar la agresividad de sus miembros para poder establecer relaciones sociales. En otras palabras, la cortesía presupone y se justifica por esa agresividad. Dentro de esta teoría, los individuos presentan dos propiedades básicas: la racionalidad y la imagen pública. La característica de racionalidad explica que los hablantes busquen la máxima claridad y eficacia en la interacción (principio de cooperación de Grice), mientras que la de imagen pública (face) alude a la necesidad de la cortesía.

Brown y Levinson derivan su teoría del concepto de imagen (Goffman, 1967), pues la necesidad de mantenerla (salvarla de amenazas) es esencial para explicar el uso de las estrategias de cortesía. Como expresa Haverkate (1994: 19), este concepto de imagen "justifica la hipótesis de que la interacción social en general y la verbal en especial impone a los participantes la norma de que respeten mutuamente lo que Brown y Levinson llaman "face-wants"." La imagen pública tiene dos vertientes, la negativa (deseo de no ver su campo de acción limitado o condicionado) y la positiva (deseo de ser reconocido y apreciado). El principio se basa en la idea que todos los individuos tienen su imagen, y que si quieren mantener buenas relaciones sociales, tienen que defender la del otro tanto como la propia. Ahora bien, existen acciones que amenazan la imagen pública (AAIP o facethreatening acts), que podrían crear conflictos entre los participantes. Es precisamente para evitar o mitigar esa posible amenaza que los hablantes emplean la cortesía.

De acuerdo con Haverkate (1994), los hablantes son "conscientes de su propia imagen y de la de su interlocutor" (1994: 35), así como de las posibles amenazas que sus actos conllevan. A partir del principio de racionalidad, "dado un objeto comunicativo determinado, el hablante 
escogerá la estrategia de cortesía que, con menor coste verbal, alcance ese objetivo". (Haverkate, 1994: 37). Esto se propone en el marco de los actos que amenazan la imagen del interlocutor (como los exhortativos), en los cuales el hablante deberá invertir un mayor esfuerzo, de manera que logre que su interlocutor coopere y actúe en beneficio del hablante.

Este balance, si se parte de la perspectiva egocentrista, podría aplicarse no solo a los actos no corteses, sino también a los corteses. Con las invitaciones, el hablante asumirá un costo para hacer algo en beneficio del otro (arriesgará tanto su imagen positiva como la negativa), porque sabe que, directa o indirectamente, obtendrá algún beneficio a cambio. Sin embargo, se podría incluso cuestionar en beneficio de quién se realiza el acto. El siguiente ejemplo sirve de ilustración:

21 E: y:: ¿preferís invitar o recibir invitaciones? / ¿invitar o que te inviten?

26 H3: diay ((yo so o sea sí)) depende del interés no porque si uno es el interesado entonces uno invita ¿no?

$28 \mathrm{H} 3$ : y si la otra persona es la interesada entonces...

Además, Haverkate (1994) menciona, con respecto a las invitaciones, que quien recibe la invitación contrae la deuda de restablecer el balance costo-beneficio. Este punto se discutirá cuando se evalúe la amenaza que implica la invitación a la imagen negativa del oyente.

La distinción que propone Haverkate (1994) entre los actos de habla corteses y los actos de habla no corteses se basa en el balance costo-beneficio, según el cual si "la realización del acto redunda en beneficio del interlocutor, el acto es cortés" (Haverkate, 1994, p. 77). Es decir, un acto típicamente cortés es aquel que resulta en un mayor beneficio para el destinatario y un mayor costo para el hablante. Estos actos no necesitan mitigarse porque intrínsecamente resultan en beneficio del interlocutor. Además, estos actos contienen inherentemente cortesía positiva, como se puede observar en el siguiente ejemplo:
(3) $111 \mathrm{E}: \mathrm{y}::$ ¿te parece que es cortés / hacer una invitación?

112 H1: sí:

$114 \mathrm{H1}$ : // diay porque es como:: hacerle sentir a la gente que:: uno los toma en cuenta y que:: son importantes para uno.

Con respecto a la mitigación en los actos corteses, menciona Haverkate que "la realización indirecta del cumplido no puede explicarse como intento por parte del hablante de atenuar la fuerza de su acto de habla. La mitigación no cumple ningún papel en la realización del cumplido, puesto que, en virtud de su objeto ilocutivo, es un acto de habla cuya realización no conlleva consecuencias negativas para el oyente" (1994: 91). De acuerdo con Haverkate, el objeto ilocutivo de las invitaciones (al igual que el de los cumplidos, ambos actos de habla "prototípicamente" corteses) también está orientado hacia el beneficio del interlocutor; sin embargo, surgen dos cuestiones. En primer lugar, como se sugirió anteriormente, no es tan claro en beneficio de quién se realizan las invitaciones; y en segundo, se propone que el acto de invitar sí conlleva una amenaza para el oyente. Ahora bien, si el acto amenaza la imagen, tal como sucede con los actos de habla no corteses, el hablante puede elegir estrategias para mitigar o atenuar esta imagen y mostrar cortesía negativa.

Como se verá más adelante, la invitación comparte rasgos con los actos no corteses, e incluso adopta formas exhortativas y asertivas en su realización. Igualmente, se necesita un acto preparatorio, con el que vamos midiendo la voluntad y disponibilidad del interlocutor para ver si es seguro plantear la invitación o no. Este "preludio", junto con las estrategias que se emplean para mitigar las invitaciones, se analizarán en apartados siguientes.

\section{Estudios sobre la invitación en el ámbito hispanohablante}

Las invitaciones, por su carácter comisivo e interaccional, son un acto bastante complejo. 
Ferrer y Sánchez Lanza (2000) hacen un estudio de este acto dentro de la teoría de actos de habla de Searle, las máximas conversacionales de Grice, y las teorías de cortesía verbal de Leech, Brown y Levinson y Haverkate. Las autoras realizan una caracterización del acto en el ámbito argentino, describen su estructura y proponen una tipología para clasificarlos. Este artículo será clave para la caracterización del acto de habla en el ámbito costarricense de acuerdo con la muestra obtenida, por lo que se profundizará en el contenido del mismo para realizar el análisis de los datos.

Dentro del campo costarricense, se encuentra la tesis de maestría de Urbina Vargas (2007), en la cual la autora hace un análisis de las respuestas preferidas y no preferidas para aceptar y rechazar una invitación según la tipología de las invitaciones propuesta por Ferrer y Sánchez Lanza (2000). Este trabajo está orientado hacia el análisis de las estrategias para la enseñanza del español como lengua extranjera.

Barros García (2010) realiza una revisión de las invitaciones como actos que muestran cortesía valorizada; es decir, son actos que refuerzan los lazos sociales en una comunidad. La autora propone que la cortesía en la cultura española tiende más hacia la valorización de la imagen que hacia la mitigación de las posibles amenazas. Realiza una caracterización de las estrategias comunicativas y las situaciones contextuales en que tienen lugar las invitaciones, que son necesarias para la comprensión de este acto como una muestra de cortesía valorizadora.

Por último, se tomó en cuenta el artículo de Gil (2005) sobre la amenaza e invasión a la imagen que sufren los hablantes con los distintos actos de habla. El autor no considera solamente los actos de habla que Haverkate (1994) llama "no corteses", que son la exhortación y la aserción, sino que propone que todos los actos implican intrínsecamente una amenaza para las imágenes tanto del hablante como del oyente. Por esta razón, Gil propone clasificar los actos de habla en actos no descorteses y actos descorteses. Esta caracterización resultó útil para el presente trabajo porque permitió analizar la amenaza de imagen de los actos "corteses", entre los cuales se encuentran los actos comisivos. Estas amenazas se presentarán más adelante con el análisis de los datos.

\section{Marco metodológico}

Para el presente trabajo, se realizó una entrevista de hábitos sociales. Según la clasificación de Kasper (2000) (tomada de Murillo, 2008: 58) la entrevista es una técnica de recolección de datos orientada hacia la metapragmática, y no hacia la interacción, comprensión o producción de habla. En otras palabras, los datos recolectados representan lo que los hablantes piensan sobre el acto de habla y lo que consideran que dirían a la hora de realizar el acto, pero no se puede saber si es lo que realmente dirían en una situación comunicativa concreta. Siguiendo la clasificación de Kasper, la entrevista es una técnica que implica interacción con el investigador. Este punto es importante, porque las preguntas y el orden en que se plantearon se modificó de acuerdo con las respuestas que daban los participantes.

La entrevista tenía un enfoque tanto sociopragmático como pragmalingüístico, por lo que se tomó como base un cuestionario de hábitos sociales (Murillo, 2008) (Anexo 1). Estos son formularios que pretenden determinar el comportamiento social de los participantes. Por un lado, se pregunta sobre lo que el informante considera cortés o descortés de acuerdo con sus valores y creencias. De este modo, se puede realizar un acercamiento a las normas sociales que rigen el comportamiento de una comunidad. Por otro lado, se les solicita que ofrezcan ejemplos de lo que dirían en una determinada situación. Para este estudio, no se presentaron situaciones comunicativas concretas 
con información contextual que permitiera una determinada respuesta, sino que se planteó de manera abierta. Algunos informantes especificaron en qué casos utilizarían ciertas formas, mientras que en otros casos esta información se obtuvo de la interacción con la entrevistadora. Por último, algunos informantes no especificaron las variables que determinarían la selección de la forma lingüística que ofrecen para ejemplificar la realización del acto de habla.

Los cuestionarios de hábitos sociales sirven para describir una comunidad sociocultural porque "las respuestas muestran el comportamiento social compartido de un grupo en relación con sus creencias, valores o actitudes, a pesar de que estas no pueden considerarse como datos reales, sino que constituyen información metapragmática" (Hernández Flores, 2003, citada por Murillo, 2008: 62). Ya que no son datos "reales", es decir, enunciados emitidos en una situación real, sirven más que todo como punto de partida para estudios posteriores del habla real (Murillo, 2008). Como señala Murillo, la información metapragmática permite delinear lo que los hablantes consideran como cortés. Con respecto a este punto, puede que respondan según lo que piensan que es "correcto", lo cual podría tergiversar los datos, y no lo que realmente harían en una situación concreta. Aún así, las respuestas ofrecen información sobre el comportamiento social, lo cual permite realizar una descripción inicial del acto de habla. Esta puede ser verificada posteriormente con la recolección de datos reales.

Siguiendo el planteamiento de Hernández Flores, los cuestionarios de hábitos sociales son útiles para determinar tres aspectos del comportamiento social de los participantes: "cómo son los modelos de realización pragmalingüística de distintos actos de habla y cómo varía el comportamiento considerado adecuado en relación con las características de los interactuantes y qué valores están detrás de los comportamientos mencionados en las respuestas" (Murillo, 2008: 62-63). En este caso, el objetivo es analizar el modelo de realización del acto de habla de la invitación, así como los valores que motivan la realización de este acto, los cuales se analizaron, como se mencionó anteriormente, desde la perspectiva del egocentrismo. No se enfatizó en las variables que dependen de las características de los participantes ni de la situación comunicativa en que se realiza el acto; no obstante, en algunos casos se mencionan estas variables, ya que es prácticamente imposible hablar de pragmática sin hacer alguna referencia a los aspectos contextuales.

Murillo (2008) señala que uno de los inconvenientes de los cuestionarios de hábitos sociales aplicados por Hernández Flores, Boretti y Murillo en el ámbito hispanohablante fue que se trataba de cuestionarios escritos que preguntaban por formas de comportamiento orales. En el caso de esta investigación, la realización de entrevistas permitió disminuir esa interferencia y captar de manera más "natural" lo que se diría para realizar el acto de habla en cuestión.

La herramienta empleada se denominó “entrevista de hábitos sociales" porque se utilizó un cuestionario guía basado en la descripción que Murillo (2008) realiza de los cuestionarios de hábitos sociales, pero se aplicó de manera oral. Se entrevistó a diez participantes, cinco mujeres y cinco hombres costarricenses entre 20 y 30 años. Las entrevistas fueron grabadas sin el previo conocimiento de los informantes para lograr una mayor naturalidad en las respuestas; luego se les informó que habían sido grabados y que sus respuestas serían anónimas (grabaciones disponibles a petición). Las grabaciones fueron transcritas utilizando los siguientes lineamientos (adaptado de Tusón (1997) y Briz Gómez (1998)):

1. Se enumeraron las líneas a la izquierda.

2. Se utilizó la grafía normal.

3. Se emplearon los siguientes símbolos prosódicos: 
CUADRO 1

Símbolos prosódicos utilizados en la transcripción de entrevistas Simbología empleada

\begin{tabular}{|c|c|c|c|}
\hline ¿? & Entonación interrogativa & $\S$ & Sucesión inmediata sin pausa apreciable \\
\hline$i !$ & Entonación exclamativa & [ ] & Solapamiento en dos turnos \\
\hline ... & Descenso en la voz & (RISAS) & Cuando hay risas \\
\hline I & Pausa breve & $(())$ & Palabra ininteligible \\
\hline // & Pausa mediana & ((palabra)) & Palabra dudosa \\
\hline //I & Pausa larga & $((\ldots))$ & Interrupción mecánica o intervención no pertinente \\
\hline MAYÚS & Énfasis & ${ }^{\circ}()^{\circ}$ & Palabra o frase se dijo bajo y casi no se escucha \\
\hline : & Alargamiento de un sonido & cursiva & Palabra o frase citada \\
\hline
\end{tabular}

\section{$5 \quad$ Resultados y discusión}

A continuación se presenta un cuadro con la información básica de los participantes:

CUADRO 2.

Información básica de los participantes

\begin{tabular}{lllll}
\hline Informante & Lugar de procedencia & Edad & Lugar de residencia & Nivel educativo \\
\hline Mujer 1 & Pérez Zeledón & 23 & San Pedro & Bachillerato universitario \\
\hline Mujer 2 & Tibás & 22 & Desamparados & Bachillerato \\
\hline Mujer 3 & Tibás & 23 & Tibás & Cursando bachillerato universitario \\
\hline Mujer $\mathbf{4}$ & Tres Ríos & 21 & Tres Ríos & Bachillerato \\
\hline Mujer 5 & Coronado & 23 & Coronado & Cursando bachillerato universitario \\
\hline Hombre 1 & Curridabat & 28 & Curridabat & Cursando bachillerato universitario \\
\hline Hombre 2 & Limón & 26 & Heredia & Licenciatura \\
\hline Hombre 3 & Heredia & 24 & San José & Cursando tercer ciclo \\
\hline Hombre 4 & Alajuela & 22 & Alajuela & Cursando bachillerato universitario \\
\hline Hombre 5 & Curridabat & 26 & San Pedro & Cursando bachillerato universitario \\
\hline
\end{tabular}

Las entrevistas se trabajaron con el programa Microsoft Excel, porque este enumera las líneas a la izquierda. De esta manera, cada emisión de los distintos participantes queda enumerada en una línea independiente (transcripciones disponibles a petición). Los resultados de las entrevistas se ordenaron en cuadros con las columnas de "pregunta" y "respuesta" para facilitar el análisis. Se incluyen las preguntas tal como se hicieron en la entrevista; como se mencionó antes, su forma o el orden en que se realizaron varió en algunos casos según las respuestas de los participantes (cuadros con preguntas y respuestas disponibles a petición).

A continuación se hará una valoración de los resultados a partir de la propuesta del acto comisivo de la invitación de Ferrer y Sánchez 
Lanza (2000) para determinar hasta qué punto la muestra concuerda con la caracterización del acto que hacen las autoras.

\subsection{Contraste con la propuesta de "Actos de habla comisivos: la invitación"}

Ferrer y Sánchez Lanza (2000), definen la invitación como: "un acto comisivo en el que el hablante tiene la intención de comprometerse a hacer algo en beneficio del otro." (2000: 57). La Mujer1, por ejemplo, cuando se le pregunta por qué invita, responde lo siguiente:

(4) $50 \mathrm{M1}$ : (RISAS) // di porque:: // porque quiero hacer algo // o sea, talvez, no sé, por querer salir, o por querer ir a comer, o por querer que vayan a mi casa [o:]

De la muestra obtenida, no es tan claro que el hablante se proponga a hacer algo en beneficio del otro. Entre los motivos citados, se menciona:

(5) $100 \mathrm{H1}$ : para compartir con la gente

(6) $64 \mathrm{M} 2$ : (SILENCIO)

66 M2: diay porque porque // diay no sé porque es importante ¿no? compartir con la gente / ni modo que ((así salga)) uno y haga todo solo / qué feo // [bueno pero...]

68 M2: [para mí] jexacto! / para Mí:: / porque no me gusta estar sola ni me gusta hacer nada sola

(7) 74 M3: no porque es bonito digamos llegar y proponer actividades o pensar en salir o así

76 M3: porque es interesante ir a algún lado / a tener una actividad random así

79 E: ¿pero eso di lo podrías hacer sola?

80 M3: no / difícilmente porque no me gustaría ir sola al cine o al (ENTRE RISAS) (()) a la playa o algo así

(8) 96 M4: ¿por qué los invito? di porque / me gusta / no sé / hay actividades que me gustaría pasar con ellos y me gustaría ir a algún lugar pero no quiero ir sola entonces invito a la otra persona

Afirman Ferrer y Sánchez Lanza que: "Es un acto ilocutivo que propone estimular a la otra persona a participar en algo o, dicho de otro modo, es inducir a alguien a que realice alguna acción que le resulte grata o beneficiosa [...]" (Ferrer y Sánchez Lanza, 2000: 39). Por ejemplo, el Hombre2 dice que invita porque:

(9) $72 \mathrm{H} 2$ : diay por muchas razones por compartir algo / algo que tengo o algo que quiero que la gente conozca o algo así siempre es por...

74 H2: por... esas ganas de que alguien haga algo que que a mí me gustó / o que me gustaría hacer

Sin embargo este no es siempre el caso, como se puede observar en el comentario de la Mujer1:

(10) 196 M1: entonces si otra persona me invita / puede ser que o: no quiera o: no pueda o: // entonces sí en realidad me gusta más cuando lo hago yo porque yo lo controlo

202 M1: §sí sí pero entonces puede ser como que: como que controlo el costo que yo tendría que hacer

204 M1: porque si alguien me invita, puede ser que, depende del caso, tenga que sacrificarme yo / o // o tenga que rechazar.

El acto de invitar comunica cortesía positiva porque el hablante se compromete a hacer algo en beneficio del interlocutor, y se apega a las máximas de cortesía de tacto y de generosidad propuestas por Leech. Dentro de la perspectiva egocentrista, el hablante se compromete a hacer algo, pero busca siempre un beneficio para sí mismo. Al Hombre3, cuando se le pregunta que por qué invita, responde: 
(11) 82 H3: diay::: / como te dije si me interesa alguien o me gusta di pues porque me gusta

84 H3: en el ámbito / personal verdad / si es alguien / del ámbito profesional / pues invito para ver qué negocio podemos llegar a hacer verdad o que...

En este caso, podríamos remitirnos a la referencia a Freud (Haski-Leventhal, 2009): puede que se aprenda a hacer actos por los otros, a ser altruista, pero si se hace es porque se sabe que se va a obtener un beneficio de esta acción. Desde esta perspectiva, incluso se podría poner en duda si cabría situar la invitación dentro de los actos de habla corteses, como lo hace Haverkate (1994), pues está orientado al beneficio del hablante (y motivado por este).

Ferrer y Sánchez Lanza señalan que la respuesta "no marcada" es la aceptación; sin embargo, indican que no se puede aceptar de inmediato para no parecer aprovechado; es decir, "se supone que un interlocutor cortés, educado y conocer de las normas de comportamiento social, apela a un juego o ritual negociativo entre aceptación y rechazo [...] (Ferrer y Sánchez Lanza, 2000: 41). Este no parece ser el caso en las entrevistas realizadas:

(12) 213 E: ¿pero si vos querés así decís inmediatamente que sí?§

216 H3: sí por supuesto / cuando a uno le interesa algo / cuando a uno le interesa algo uno hace lo que sea

Como se puede observar, se acepta de manera inmediata si es solo una invitación para hacer algo, pero si es una invitación que incluye cubrir los gastos, sí hay más resistencia. Sobre este punto se volverá más adelante cuando se discuta el uso del verbo invitar.

La respuesta "marcada" o "no preferida", por otra parte, es el rechazo. Se emplean diferentes estrategias para que no sea tan directo: dilaciones verbales o no verbales y explicaciones que justifican la elección del acto despreferido. En la muestra, la Mujer3 se expresa al respecto cuando le preguntan qué es más fácil, aceptar o rechazar una invitación:
(13) 50 M3: porque usualmente uno la puede aceptar / o uno la puede rechazar aceptándola

52 M3: diciendo sí sí yo te aviso

54 M3: o sí sí ahí vemos

56 M3: o sea uno la está / rechazando / pero no le está diciendo sino que es implícito.

De esta manera, se mitiga la amenaza a la imagen positiva que significa el rechazo de la invitación.

Por otra parte, Haverkate (1994) menciona que, así como es cortés realizar una invitación, también es cortés rechazarla, porque la realización de la misma implica un costo para el interlocutor y una posible deuda para el oyente. De la muestra obtenida, se observa que este no es el caso; es decir, que no es cortés rechazar:

(14) $87 \mathrm{E}$ : y ite parece cortés rechazar una invitación?

88 H2: /// depende de la de la // ahorita no se me ocurre en qué momentos podría ver cortés el rechazar una invitación

90 H2: yo pienso que no no [no]

92 H2: no es cortés rechazar

Como se puede observar, prevalece la amenaza a la imagen positiva del hablante cuando se rechaza su invitación, por lo que no se considera cortés el rechazo. Más bien, es cortés rechazar cuando:

(15) 112 H3: este:: / pues desde ese punto de vista pues el rechazo indirecto llamémosle así pues sí es cortés si no te interesa alguien porque no le vas a hacer perder el tiempo ni el dinero.

(16) 65 E: e:: ¿y te parece cortés rechazar una invitación?§

66 M5: §sí

68 M5: porque a veces digamos / me están rechazando me están invitando y lo más cortés que puedo hacer es decirle $\mathrm{NO} /$ en lugar de engañarlos. 
M5: [o decirles] sí voy a llegar y es mentira

M5: o / decirle que sí si voy a estar incómoda

\subsubsection{Estructuras sintácticas empleadas}

Ferrer y Sánchez Lanza (2000) proponen que la estructura sintáctica de la invitación puede ser: verbos performativos, actos de habla asertivos e interrogativos y actos de habla exhortativos. En cuanto a la tipología, la invitación puede ser directa o indirecta según la realice el hablante hacia su interlocutor o por medio de un intermediario, y explícita o implícita, según se emplee un verbo performativo o no. En este punto, cabe señalar que el uso del verbo performativo tiene un significado particular, por lo que todas las invitaciones serían implícitas a menos que se quiera dar a entender que quien realiza la invitación se compromete a cubrir los gastos de la acción que se propone realizar:

(17) $127 \mathrm{E}$ : [y digamos] como para ir a comer o algo

128 M1: (ENTRE RISAS) vamos a comer

129 M1: (RISAS) pero no la invito a comer // es que podría ser que a comer / la invito a comer si implique que yo vaya a pagar

En este caso, sí aplican las reglas del "ritual negociativo" entre aceptación y rechazo que proponen Ferrer y Sánchez Lanza (2000: 41):

“1. No aceptar inmediatamente la invitación o auto beneficio.

2. Rechazar la invitación para no amenazar la imagen negativa de A.

3. Aceptar la invitación para no ofender la imagen positiva de A."

En el caso de 2., se podría proponer "Rechazar para minimizar el costo (real, económico) de A", por lo que se puede observar de los siguientes ejemplos:

(18) $165 \mathrm{E}$ : ¿y si por ejemplo la van a invitar a:: / que la invitan así que van a pagar por usted.
167 E: rechaza o acepta o::

168 M1: // yo creo que:: / uno a veces como que rechaza por por por protocolo, digamos

170 M1: entonces uno siempre dice ay no no, tranquilo, yo pago, entonces la otra persona dice ay no importa, yo la invité, yo pago entonces diay (RISAS) (ENTRE RISAS) está bien

(19) $209 \mathrm{E}: \mathrm{mjm} / \mathrm{y}$ digamos si te van a invitar por ejemplo a comer o algo así y te dicen ay eh / yo te invito yo pago por vos // ¿vos decís sí? o::

210 M2: no / no me gusta

213 E: pero: digamos... / rechazás y que te insistan y eventualmente aceptás ¿o no?

214 M2: no no rechazo / sino que le digo bueno vamos pero no yo pago tranquilo / ${ }^{\circ}$ yo pago mis cosas $)^{\circ}$

Estas normas, como se mencionó anteriormente, aplican en el caso de pagar, pero en el acto de invitar:

(20) $165 \mathrm{E}: \mathrm{m}:$ : y digamos si a vos te invitan e:: / y vos querés ir decís sí / o decís ay no no y esperás que te insistan y vos $\mathrm{m}:$ : bueno

166 M3: ah no no usualmente es como sí sí puedo [perfecto]

167 E: y digamos $¿$ si te van a invitar como que te van a pagar algo?

170 M3: no ahí si hay un poco de resistencia / uno dice ay no qué pena y ya si vuelven a insistir es como ok está bien

172 M3: porque tampoco hacerse como / el rogado (RISAS)

En este caso la Mujer3 difiere de la Mujer2, quien simplemente no aceptaría la invitación. La Mujer3 presenta "resistencia" por "protocolo", pero eventualmente acepta.

Invitar como "pagar" sí sería un acto prototípicamente cortés, porque implica un mayor costo por parte del interlocutor (un costo material, económico); en otras 
palabras, sí se tiene que "invertir", literalmente, en la otra persona:

(21) $39 \mathrm{E}:$ ¿y por qué no te gusta que paguen por vos?

42 M4: porque::: / cómo una persona que / no se ¿cómo otra persona va a gastar dinero en uno? $/{ }^{\circ}(\text { no sé... })^{\circ}$

49 E: bueno pero si vas a pagar por otra persona ¿por qué lo harías?

50 M4: // mmm::: talvez porque la otra persona no tenga dinero para para pagar

51 E: mjm / [¿y así sólo como por invitar?]

52 M4: [o porque] / o porque me cae muy bien la persona

54 M4: y porque me gustaría estar con ella entonces obviamente uno sí...

56 M4: sí le pagaría

58 M4: y si la estoy invitando es porque quiero estar... pasar tiempo con ella

Con respecto a la "deuda" adquirida por aceptar una invitación, las respuestas varían:

(22) 103 E: y::m:: / si a vos te invitan a hacer algo / ¿después te sentís como comprometida a devolver la invitación?

104 M2: sí

(23) 133 E: bueno eh::: si::: si a vos te invitan / después vos te sentís comprometido a devolver la invitación?

\section{H1: no}

Sin embargo, cuando hay una inversión económica, los participantes sí sienten que necesitan restablecer el equilibrio:

(24) $115 \mathrm{E}$ : eh:: si a vos te invitan ¿después te sentís comprometido a devolver la invitación?

116 H3: e:: pues sí sí sí la verdad siento que es parte de ¿no? si si si un día pues sí te invitan y más este si invito a alguien económicamente / ya eso desde el punto de vista amigos / así porque mujeres yo nunca dejo que paguen jamás.

228 H3: eso:: / jamás / pero este:... / eh si un amigo un ejemplo di un día me invitó en un bar o así yo sí siento el compromiso de que si en algún momento vamos sí sí ((exactamente))

\subsubsection{Estrategias de mitigación}

Además del uso del verbo performativo, Ferrer y Sánchez Lanza (2000) mencionan el acto de habla asertivo o interrogativo y el acto de habla exhortativo como posibles estructuras de la invitación. Estos actos se encontraron en las respuestas de los informantes cuando se les preguntó que cómo planteaban una invitación:

(25) $122 \mathrm{M} 1$ : porque si fuera el caso de ir a mi casa en realidad diría como:: diay vamos a mi casa.

124 M1: o:: / diría hagamos algo

En este caso, la invitación tiene forma de exhortación y, en el caso de hagamos algo, se atenúa con el modo subjuntivo, que indica la posibilidad de realización del acto.

(26) $188 \mathrm{H1}$ : mirá vamos a ir a tal lado este fin de semana / ¿te gustaría ir?

Aquí, se presenta en forma de aserción seguida de una alusión a los gustos del oyente utilizando el condicional de cortesía. Esta estrategia de desfocalización del tiempo deíctico se emplea para mitigar tanto los actos exhortativos como asertivos, ya que amenazan la imagen del interlocutor.

Con respecto a la atenuación de las invitaciones, Ferrer y Sánchez Lanza (2000: 49) dicen: "La invitación, acto de habla esencialmente favorable para el interlocutor, no necesita, por lo mismo, ser atenuada; sin embargo, cuando ella está dirigida a lograr la participación o colaboración de alguien en un hecho, acontecimiento o tarea que puede resultarle no tan grato o representar algún tipo de esfuerzo para él, el que invita prefiere no imponerse y la formula de tal modo que deja una 
especie de puerta abierta para que su interlocutor la rehuse (sic) sin sentirse mal por ello."

Algunas de las estrategias mitigadoras son: el uso del modo potencial (o condicional de cortesía, ver ejemplo 27), pedir la opinión del oyente, utilización de perífrasis, utilización del verbo querer y empleo de la forma de interrogación. Además, la formulación de las invitaciones se hace de manera implícita.

90 M3: sí / me parece muy cortés ((decir)) y mirá voy a hacer tal y tal cosa ¿querés ir conmi::ggo?

Cabe señalar que, como se mencionó anteriormente, el verbo performativo invitar se emplea casi exclusivamente con el significado de 'cubrir los gastos', así que para no dar a entender eso, los hablantes tienen que recurrir a una forma implícita para plantear la invitación. En este sentido, todas las invitaciones estarían mitigadas. A este respecto, Ferrer y Sánchez Lanza indican que "[a]lgunos autores consideran que la invitación puede ser amenazante para la faz negativa del receptor, razón por la cual, según ellos, se debe formular de manera atenuada [...]" (2000: 57).

Así, no sería extraño escuchar una invitación como "Quería preguntarte si te gustaría ir por un café o algo... no sé, digo yo, si te parece... ¿o preferirías ir a comer? no sé, decime vos, lo que te parezca mejor". En este caso, contrario a lo que propone Haverkate (1994: 91) en relación con los cumplidos, la realización indirecta del acto de habla sí podría deberse a un deseo del interlocutor de atenuar las amenazas que la invitación podría implicar. El Hombre3 dice respecto a las invitaciones indirectas:

(28) 194 H3: o mirá / ¿qué tienes que hacer? / son dos cosas casi que que el qué tiene que hacer es quiero salir contigo pero indirectamente $(())$

La Mujer5 ofrece en la entrevista un ejemplo de invitación que se podría considerar un acto de habla indirecto. En este caso, se trata de una aserción, cuya fuerza ilocutiva primaria (Searle, 1975) es la invitación:
(29) 134 M5: vea por ejemplo ahora estoy invitando a un amigo a que vaya conmigo a desert (sic) factory

138 M5: bla bla bla bla bla // ah bueno ve por ejemplo / eso es el de antes yo le mandé hay plan de mau y mío de comer helado a las cinco pero a las seis me tengo que ir.

Ahora bien, otro de los rasgos que comparten las invitaciones con los actos exhortativos es que usualmente cuentan con una secuencia previa a la realización del acto. En el caso de las exhortaciones, por ejemplo, se puede hacer un cumplido para crear cortesía positiva antes de realizar el acto potencialmente amenazante de una petición. En el caso de las invitaciones, se alude por ejemplo a los intereses del interlocutor:

(30) 186 M2: siempre hay una secuencia antes

190 M2: es que no sé que puede ser talvez uno se pone a hablar de películas y cosa así / y después ya sale ay mirá van a dar tal película / vamos o algo así

192 M2: [o hace] u que no salimos / digamos yo tengo amigas que me ponen hace $u$ que no salimos.

Esta secuencia preparatoria también funciona como un mecanismo para defender la imagen positiva del hablante, o "para que no le pueda decir que no". Aquí, el uso de esta presecuencia no sería por cortesía, sino que tendría una motivación egocentrista de proteger la imagen pública:

(31) $174 \mathrm{H} 2$ : le preguntaría ¿y qué tiene que hacer mañana? o algo así (RISAS)

176 H2: sería la forma más así como para que...

178 H2: ya ella dijo que no va a hacer nada entonces ya... (RISAS).

De esta manera, se disminuyen las posibilidades de rechazo por medio de las preguntas a la disponibilidad de la persona. Sirve también para no exponer la imagen:

(32) 189 E: y ese preámbulo / ¿como para qué sirve o qué qué es o::? 
190 H3: como para no ser directo simplemente por por vergüenza

192 H3: de llegar a decirle mirá ¿quiere salir conmigo?

Al igual que sucede con las prepeticiones (Portolés, 2004), esta secuencia previa a las invitaciones puede funcionar como el acto mismo:

(33) 182 H2: porque porque detrás de esas palabras hay hay // hay ciertas cosas que uno / presupone también

184 H2: que que van a ir saliendo por ejemplo si si yo le pregunto este / ¿qué tiene que hacer mañana? / y ella ella va a saber las intenciones al final [ella

186 H2: ¡tiene] que saber! que es porque después viene este:: ¿puede salir conmigo? entonces ¡basta! y es una forma muy / como muy / este muy bonita hasta de que a uno le digan que que que no puede salir mañana que le digan no mañana tengo tal cosa / incluso hasta como para usted tantear el terreno / porque si a usted le dicen no mañana no puedo pero pero pasado mañana este:: este jestoy libre!

El uso de la presecuencia como el acto mismo podría considerarse un acto de habla indirecto, tal como los considera Searle (1975). En un ejemplo como: "¿qué tiene que hacer mañana?", podría sugerirse que el acto ilocutivo primario es una invitación y el acto ilocutivo secundario es una pregunta. Se entiende como acto ilocutivo primario la invitación, porque en este caso la persona a la que se le hace la pregunta no va simplemente a responder qué tiene que hacer al día siguiente. Como sugiere el Hombre2, la respuesta a esta pregunta podría ser: "no mañana no puedo pero pero pasado mañana este:: este jestoy libre!”. Como señala Portolés (2004) con respecto a las prepeticiones, el uso frecuente de este "preludio" hace que se responda directamente a la invitación (ver ejemplos 29 y 30).

Por último, las invitaciones comparten la forma de primera persona plural con las exhortaciones mitigadas que emplean la estrategia de la referencia pseudoinclusiva (Haverkate, 1994, 183). En el caso de las aserciones, el hablante no se incluye realmente en la realización del acto. Por el contrario, el uso del plural en las invitaciones es incluir al interlocutor en la acción que se va a realizar. Cuando a la Mujer3 se le pregunta si es necesario hacer invitaciones, ella responde:

(34) 86 M3: sí porque uno / o sea cuando hacés invitaciones sabés que estás acom / pidiéndole acompañamiento a la otra persona.

88 M3: porque no es lo mismo decir VAMOS a tal lado a decir YO VOY A IR

Como se ha venido comentando a lo largo del análisis, el acto de invitar amenaza potencialmente las imágenes tanto del hablante como del oyente. A continuación, se analizarán las amenazas a partir de la propuesta de Gil (2005) en relación con los actos de habla comisivos.

\subsection{La invitación como un acto que amenaza la imagen}

Se dijo anteriormente que la invitación es un acto prototípicamente cortés porque el hablante $(\mathrm{H})$ realiza una acción en beneficio del oyente (O). Sin embargo, como ya se evidenció en apartados anteriores, esta definición podría cuestionarse. Sirve como ejemplo las amenazas que detecta la Mujer4 en relación con el acto de invitar:

(35) $63 \mathrm{E}$ : eh: te incomoda:: invita::r o que te inviten / o ninguno / o qué te incomodaría

$64 \mathrm{M} 4: / / \mathrm{mmm}$ me incomodaría invitar y que me lo rechazan [que me lo rechacen]

66 M4: ¡sí::.:!... y me incomodaría que alguien me invite y yo no quiera salir con él

5.2.1. Amenaza 1: "El acto comisivo amenaza la imagen positiva de $\mathrm{H}$ porque $\mathrm{H}$ admite que desea hacer algo que va a beneficiar a O. Así, H manifiesta un supuesto sobre su capacidad y aun sobre su condición social” (Gil, 2005). 
Tanto la Mujer2 como el Hombre2 se refieren al respecto:

(36) $48 \mathrm{M} 2$ : (RISAS) muy feo que lo rechacen a uno

(37) 47 E: ¿cuál es el problema con rechazar?

$48 \quad \mathrm{H} 2$ : herir / sentimientos al final

En algunos casos, se reconoce la amenaza a la imagen positiva del hablante, pero prevalece salvar la imagen negativa propia; es decir, la autonomía:

(38) $53 \mathrm{E}$ : eh:: ¿qué te parece que es más fácil aceptar o rechazar una invitación?

54 H3: depende

56 H3: de la chavala

58 H3: porque diay / si si es si a uno le gusta pues muy fácil verdad y si no te gusta pues / qué difícil (RISAS)

60 H3: también a la hora de decirle incluso que no verdad porque di uno no quiere / este / herir los sentimientos de nadie verdad

Con respecto a la dificultad de rechazar, se recurre a lo que Haverkate llama una mentira piadosa: "La máxima de calidad de incumple por motivos de cortesía si decir la verdad encierra una evidente amenaza a la imagen positiva del oyente" (1994: 44). Esto se ejemplifica en el siguiente comentario:

(39) 219 E: ajá / ¿y para rechazar?

222 H3: no no como te digo uno siempre este diplomáticamente siempre se va a andar por las ramas como ay dejame ver / o te aviso e::...

224 H3: sí sí / eh eh eh o sí se inventa algo más fácil

226 H3: todo el mundo miente entonces...

5.2.2. Amenaza 2: "El acto comisivo amenaza intrínsecamente la imagen negativa de $\mathrm{H}$ porque $\mathrm{H}$ se impone hacer algo en beneficio de O" (Gil, 2005).

La Mujer1, por ejemplo, prefiere esta amenaza a la que implicaría hacer una invitación:
(40) 202 M1: §sí sí pero entonces puede ser como que: como que controlo el costo que yo tendría que hacer

$\mathrm{Si}$ se realiza una invitación por compromiso, la imagen negativa se pone en riesgo voluntariamente, porque $\mathrm{H}$ sabe que va a obtener un beneficio a cambio, como lo pone en manifiesto la Mujer4:

(41) 129 E: ¿cuál sería una invitación::: por compromiso? / en:: así como ¿en qué:: en qué casos invitarías por compromiso o:?

132 M4: bueno cuando tengo un amigo que le gusta una muchacha / y él me dice invítela invítela / pero a mí no me cae muy bien ella verdad.

134 M4: ipero él me va a dar algo a cambio si yo la invito a ella! (RISAS)

136 M4: eso sería una invitación por compromiso (RISAS)

El costo lo asume $\mathrm{H}$, pero no se podría decir que es un acto cortés, porque lo realiza pensando en el beneficio que va a obtener a cambio de sacrificar su imagen negativa.

En esta situación, si O acepta la invitación, es desfavorable para $\mathrm{H}$ (amenaza su imagen negativa), pero se favorece a sí mismo (sería egoísta porque busca el beneficio propio y no le importa la amenaza de $\mathrm{H}$ ). $\mathrm{Si} \mathrm{O}$ rechaza, es favorable para $\mathrm{H}$, y en este caso sí sería cortés rechazar.

(42) $158 \mathrm{H3}$ : pues sí creo que cualquiera que invita por compromiso / así como por puro compromiso pues está deseando que le digan ah no mirá mejor no

$160 \mathrm{H} 3:^{\circ}\left(\right.$ es algo como casi obvio) ${ }^{\circ}$

(43) 99 E: y digamos si a vos te toca invitar así como porque se enteraron / ¿preferís / que rechacen o que acepten?

100 H4: me / beneficia que rechacen

$\mathrm{Si}$ se invita por compromiso, $\mathrm{H}$ espera que $\mathrm{O}$ rechace, pero hay una obligación social. Cuando se le pregunta al Hombrel al respecto, comenta: 
(44) $150 \mathrm{H1}$ : diay que yo quiera ir con mis amigos a algún lugar y que tenga que llevar a mi novia (RISAS)

152 H1: (ENTRE RISAS) es un es un compromiso entonces diay / ¡qué pereza! pero diay le voy a decir a ella que si quiere ir (ENTRE RISAS)

154 H1: porque es un compromiso / porque ya uno está como de diay como de.... por cortesía digamos (RISAS) para que no se sienta mal

157 E: y digamos / si vos invitás por compromiso: / ¿qué preferís / que la persona acepte o que rechace?

158 H1: ¡que rechace! (RISAS) ¡estoy cruzando los dedos para que me diga que no! (RISAS)

Sin embargo, no todos sienten esta obligación:

(45) 85 E:¿vos invitás por compromiso?

86 M5: no / jamás

92 M5: bueno sí o sea yo incluso descaradamente he dicho como:: / vamos a hacer tal cosa NOSOTROS CUATRO

94 M5: y hay un cinco ahí que no está invitado yo no lo hago yo nunca invitaría a nadie por compromiso

5.2.3. Amenaza 3: "El acto comisivo amenaza la imagen positiva de $\mathrm{O}$. $\mathrm{H}$ hace manifiesto un supuesto sobre los deseos o preferencias de $\mathrm{O}$; e.g., $\mathrm{H}$ cree que $\mathrm{O}$ quiere o prefiere que $\mathrm{H}$ haga lo que dice que va a hacer" (Gil, 2005).

La Mujer2 reconoce este riesgo cuando responde que es más incómodo invitar, porque:

(46) 38 M2: sí porque no sé si después la persona no le gusta o algo así

Una invitación no se considera cortés cuando a lo que se invita no es del agrado de O, como se vio en el caso del Hombre6 (ver ejemplo 1); igualmente, la Mujer3 expresa:

(47) 32 M3: me incomodaría si es como algo del trabajo.
40 M3: m::e incomodaría si fuera como mi jefa o:

42 M3: gente muy muy lejana digamos / como...

46 M3: ${ }^{\circ}$ (sería como muy incómodo) ${ }^{\circ}$ (RISAS)

La amenaza a la imagen positiva de $\mathrm{O}$ podría incluso ser más grave que la amenaza a la imagen positiva de $\mathrm{H}$; es decir, es peor verse invitado a una situación desagradable a ser rechazado:

(48) $35 \mathrm{E}$ : ¿mjm? ah ok /¿te incomoda / invitar / o que te inviten?

36 H4: no

37 E: ¿no? / o ¿en qué situaciones te podría incomodar?

H4: em:: / digamos e:m: / bueno algún lugar al que no quiero ir o:: con gente desconocida talvez

5.2.4. Amenaza 4: "El acto comisivo amenaza intrínsecamente la imagen negativa de $\mathrm{O}$ porque $\mathrm{H}$ se impone una acción futura que afectará a $\mathrm{O}$ de manera directa." (Gil, 2005)

Esta amenaza podría analizarse desde la perspectiva del balance costo-beneficio, porque la aceptación del acto impone una acción futura para restablecer el equilibrio: $\mathrm{O}$ queda en deuda con $\mathrm{H}$. El balance en las interacciones sociales es de gran importancia para evitar los conflictos. La Mujer3, cuando se le pregunta si prefiere invitar o que la inviten, responde:

(49) 24 M3: ambas // ¿se puede esa opción? eh:: (RISAS)

26 M3: mm: porque digamos me parece justo / que haya como un balance de cincuenta cincuenta / ni uno está invitando a la gente ni que la gente lo esté invitando a uno.

En este sentido, si $\mathrm{O}$ acepta la invitación, es favorable para $\mathrm{H}$, se expresa cortesía positiva, lo acepta, pero queda en deuda y amenaza su imagen negativa. Por otro lado, si O rechaza, afecta la imagen positiva del otro pero salva la negativa propia; es decir, es favorable para sí mismo, lo cual sería una muestra del 
egocentrismo en la "cortesía" si se considera que rechazar es cortés.

En el caso que $\mathrm{O}$ acepte la invitación de $\mathrm{H}$, se podría decir entonces que sacrifica su autonomía por la afiliación. El sentido de afiliación es relevante, porque el compromiso va en ambos sentidos: $\mathrm{H}$ también está sacrificando su imagen negativa:

(50) 202 H2: sí los amigos también pues me gusta que me

204 H2: que me tomen en cuenta por lo menos para decirme este:: voy a hacer tal viaje / ((porque)) usted se siente así también que / usted es importante / que es parte de un núcleo por lo menos (RISAS).

\subsection{La función de la invitación como norma social}

Llegado este punto, cabe hacerse la pregunta ¿por qué entonces, a pesar de las múltiples amenazas, las personas invitan? Se podría decir que se reconoce la función social de la invitación: es una estrategia para mantener y estrechar los vínculos sociales:

(51) 201 M4: sí / me gusta invitar

204 M4: sí / me gusta cuando voy a ir a algún lugar / decirle a una amiga o: // (()) sí me parece bonito / y que me inviten por supuesto que claro que sí

Barros García (2010) menciona al respecto:

El carácter intrínsecamente cortés de las invitaciones las convierte en reforzadoras de las relaciones interpersonales, por ser marcadores de solidaridad entre los miembros de comunidades que comparten un mismo código de valores. Al emplearlas, el hablante reafirma su pertenencia a la misma cultura y formas de conducta, al igual que el oyente, puesto que tendrá que responder a la invitación de manera adecuada (Barros García, 2010: 10).

En este sentido, las invitaciones podrían verse como norma social, como ritual, porque "hay que". Si se invita es para fortalecer los lazos sociales. Siempre hay cierto egoísmo, "invito porque disfruto la compañía de la otra persona", pero en algún sentido, ambas ganan. Si la otra persona siente que queda en deuda es porque siente que $\mathrm{H}$ hace algo en beneficio de $\mathrm{O}$ (como en el caso que $\mathrm{H}$ pague por $\mathrm{O}$ ), pero en el caso del acto de invitar, el beneficio es mutuo. Así, las invitaciones sirven para estrechar los lazos de confianza y para acercar a las personas.

(52) $26 \mathrm{E}$ : eh y ¿por qué? / ¿por qué invitás?

27 H5: $\mathrm{m}::: /^{\circ}{ }^{\circ}$ (porque la convivencia genera lazos de confianza) ${ }^{\circ}$

El concepto de afiliación se sugiere para sustituir el de imagen positiva en este tipo de actos:

Por lo tanto, comparto la suposición de Bravo de que la confianza es una característica de la imagen afiliativa española, característica que no puede incluirse en la categoría de imagen positiva de $\mathrm{B} / \mathrm{L}$, pues aquélla supone el deseo de buscar o reafirmar la proximidad social entre las personas, y no el deseo de ser aprobado socialmente que se dice de la imagen positiva (Hernández-Flores, 2004: 123).

Varios informantes mencionaron que invitan a la familia, invitación que podría considerarse incluso una norma social para mantener las relaciones sociales. La Mujer5 comenta al respecto:

(53) $101 \mathrm{E}$ : em:: y después ¿en qué situaciones / como que se espera que la gente haga invitaciones? / así como para qué::: / [eventos]

108 M5: eh:: parie::ntes que viven muy cerca / y que hacen una fiesta / como de cumpleaños o así lo tienen que invitar a uno ((quiera o)) yo usualmente no voy pero igual me tienen que invitar

112 M5: di no es una cosa como con / con la familia usualmente hay un compromiso de que a uno lo tienen que invitar a las cosas.

\subsection{La (des)cortesía en la cortesía}

¿En dónde reside, pues la cortesía de este acto "prototípicamente cortés"? La contradicción se evidencia en lo que la Mujer2 me comentó en el transcurso de la investigación: "si le digo que sí, que soy una sobrada, si le digo que no, que 
soy una rogada". Entonces, ¿por quién se realiza el acto de invitar, por el otro o por sí mismo?

(54) 49 E: y:: ¿para vos qué es más fácil / que acepten o que rechacen?

50 H4: que acepten

52 H4: porque / no sé si decirlo así / se cumple mi voluntad [pero]

56 H4: se cumple mi plan de salida / de invitación / entonces es más fácil obviamente

Desde la perspectiva egocéntrica, la invitación no podría insertarse dentro de los actos de habla corteses porque están motivados por el beneficio de quien hace la invitación. Además, si se invita se busca algo a cambio.

(55) $175 \mathrm{E}$ : que te tomen en cuenta digamos... / o qué pensás como eso de / o ¿por qué te invitan? o / no sé

176 H4: bueno generalmente hay gato encerrado si lo invitan a uno a una fiesta de un amigo no muy cercano pero:...

Incluso se reconoce la cercanía entre el acto exhortativo, que pretende que el interlocutor realice el acto que le indica el hablante, y la invitación:

(56) 43 E: y:: ¿a quiéne:::s invitás?

44 M5: a amigos / a mi novio a hacer cosas / bueno a mi novio casi que lo obligo entonces... (RISAS)

46 M5: ${ }^{\circ}$ (no tiene mucho de invitación) ${ }^{\circ} /$ di no porque no es como vamos a tal lado sino VAMOS A IR A TAL LADO.

La diferencia está en que en la invitación, el oyente tiene la opción de rechazarla.

\subsection{Hacia una caracterización del acto cortés}

La cortesía en la invitación radica precisamente en que no es una obligación, en que se dan opciones, en que el hablante tiene la opción de rechazar:
(57) $113 \mathrm{E}:$ ok / ¿te parece que es cortés / hacer una invitación?

116 M4: sí sí

117 E: ¿por qué? (RISAS)

118 M4: cortés... / diay / no sé: // bueno le está dando la posibilidad a la persona de que / de decir no:: no quiero / no es decir vamos a tatatatata entonces bueno como dando la posibilidad de que la persona ((pueda pensarlo)) que si quiera ir o no quiera ir

120 M4: igual lo puede rechazar

Se podría plantear el carácter cortés de las invitaciones de la siguiente manera: Le doy la opción de que me deje hacer algo por mí, que también lo va a beneficiar a usted de alguna manera. Los hablantes no quieren ver su espacio invadido, y la cortesía radica en no invadir tampoco el espacio del otro.

(58) $65 \mathrm{E}: \mathrm{mjm} / \mathrm{ok} / \mathrm{y}$ ¿te parece cortés / hacer una invitación?

66 H4: sí

70 H4: eh porque:: la persona tiene la opción de aceptarla o rechazarla de acuerdo a su gusto

Así, se cumplen las tres máximas de Lakoff (1973): no imponga su voluntad y ofrezca opciones. La última, haga que el interlocutor se sienta bien reforzando los lazos de camaradería, se cumple en el sentido que las invitaciones tienen una función de afiliación, pues se realizan para "compartir" con las otras personas y para hacerlas sentir "valiosas". En este sentido, sí se podría decir que las invitaciones son un acto de habla prototípicamente cortés.

\section{Conclusiones}

El acto de invitar necesita redefinirse como un acto de habla cortés principalmente por dos razones: primero, porque la motivación para realizar el acto no es necesariamente el beneficio del interlocutor, y segundo, porque presenta diversas amenazas a las imágenes positivas y negativas tanto del hablante como del 
oyente. De acuerdo con la muestra recolectada, la satisfacción de la autoimagen (enalteciéndola o defendiéndola de amenazas) es lo que mueve el acto, pero también hay una preocupación por la imagen del otro. En el caso de las invitaciones por compromiso, quienes afirman realizarlas, dicen que lo hacen porque "muy feo con la otra persona" no invitarla. En este caso, sienten el riesgo de ser castigados socialmente, porque estaban en la "obligación" de hacerlo. En cambio, quienes no invitan por compomiso, nada más cumplen expresamente su voluntad y no se "sacrifican" por el otro. En cualquier caso, es una defensa a la autoimagen, tanto positiva (aprobación social) como negativa (no ver limitado su campo de acción), respectivamente.

A la vez, es necesario recordar que el otro piensa igual que el uno; cada uno es un yo, un ego, por lo que el acto resulta complejo y muy delicado. De la muestra recolectada, se podría sugerir que es por esta razón que se invita primordialmente a familiares y amigos; es decir, personas de mayor confianza y cercanía. Además, por la posibilidad de una realización indirecta del acto, si el interlocutor no es alguien cercano, puede ser que esa persona no entienda la invitación (por ejemplo, que decir que uno va a hacer algo sea una invitación), o puede llevar a malentendidos (¿un quería invitarte es que la persona va a realizar una invitación o solo que tuvo el deseo de hacerlo?). Igualmente, por invitar a personas cercanas, se trata con cuidado la imagen del otro, a pesar de que siempre hay una preocupación por la autoimagen. Existe, por tanto, cierto balance entre la defensa de la autoimagen y el cuidado de la imagen del otro, porque, a pesar de buscar el beneficio propio, ciertamente no es un acto expresamente descortés que intente amenazar la imagen del oyente.

En conclusión, la motivación para realizar invitaciones es en muchos casos egocentrista: porque quiero pasar un buen rato, porque no quiero hacer tal cosa sola, porque me interesa la otra persona, lo cual queda evidenciado por la muestra recolectada. Sin embargo, todos los informantes respondieron que invitar sí es un acto cortés. La cortesía radica no el beneficio al interlocutor que conlleva el acto, sino en que el interlocutor tiene la opción de rechazar (máximas de Lakoff, 1973); es cortés porque expresa cortesía negativa. Incluso se podría proponer que es doblemente cortés, porque además expresa cortesía positiva (se refuerza la imagen afiliativa): muestro interés por la otra persona, le hago saber que le tengo cariño, comparto con otros lo que tengo. A pesar de las múltiples amenazas que significa el acto, tanto para el que lo hace como para el que lo recibe, es necesario para mantener las relaciones interpersonales $\mathrm{y}$, más importante aún, es una situación en que todos podrían resultar beneficiados.

\section{Nota}

i. En las transcripciones se utilizaron las siguientes abreviaciones:

E: 'entrevistadora'

H (1-5): ‘hombre' y el número de entrevista

M (1-5): 'mujer' y el número de entrevista

\section{Bibliografía}

Barros García, M.J. 2010. "Actos de habla y cortesía valorizada: las invitaciones". Tonos digital, Revista electrónica de estudios filológicos, 19, 1-13. [WWW] URL: http://www.erevistas.csic.es/ ficha_articulo.php?url=oai:ojs.www. tonosdigital.es:article/394\&oai_ iden=oai_revista 48 .

Escandell Vidal, M.V. 1996. Introducción a la pragmática. Barcelona: Editorial Ariel, S.A.

Ferrer, M.C. y C. Sánchez Lanza. 2000. “Actos de habla comisivos: la invitación". Revista Argentina de Lingüistica, 16, 35-59. 
Gil, J.M. 2005. "La amenaza y la invasión de imagen: hacia un par de universales pragmáticos". CÍRCULO de lingüística aplicada a la comunicación (clac), 22. [WWW] URL: http://Www.ucm.es/info/ circulo/no22/gil.htm.

Haski-Leventhal, D. 2009. "Altruism and Volunteerism: The perceptions of altruism in four disciplines and their impact on the study of volunteerism". Journal for the Theory of Social Behaviour, 39: 3, 271-299. [WWW] URL: http://mgsm. academia.edu/DebbieHaskiLeventhal/ Papers/185021/A1truism_and Volunteerism_The_perceptions_of_ altruism_in_four_disciplines_and_their_ impact_on_the_study_of_volunteerism.

Haverkate, H. 1994. La cortesía verbal: estudio pragmalingüístico. Madrid: Gráficas Cóndor, S.A.

Hernández-Flores, N. 2004. “Cortesía y contextos socioculturales en la conversación española de familiares y amigos". En: Actas del Primer Coloquio el Programa EDICE, Universidad de Estocolmo, 121-127.

Murillo, J. 2008. "Sobre la metodología de investigación en estudios sobre el discurso de la cortesía: a propósito del empleo de cuestionarios de hábitos sociales". En: Actas del Tercer Coloquio el Programa EDICE, Universitat de València, 53-70.

Portolés, J. 2004. Pragmática para hispanistas. Madrid: Editorial Síntesis, S.A.

Tusón Valls, A. 1997. Análisis de la conversación. Barcelona: Editorial Ariel, S.A.

Urbina Vargas, M.S. 2007. Aceptar y Rechazar una Invitación: Estudio Comparativo de la
Competencia Pragmática de Estudiantes de Español como Segunda Lengua. Tesis de Maestría. Universidad de Costa Rica: San José.

\section{Anexo 1}

Estudio de pragmática sobre los actos de habla prototípicamente corteses

Información general:

Mujer $\quad \square \quad$ Hombre $\square$

Edad:

Lugar de procedencia:

Lugar de residencia:

Nivel educativo:

Cuestionario sobre las invitaciones:

1. ¿Realiza el acto de invitar?

2. ¿Prefiere hacerlo o recibirlo?

3. ¿Le incomoda hacerlo o recibirlo?

4. ¿Qué es más fácil, aceptar o rechazar una invitación?

5. ¿Hacia quién(es) dirige el acto de invitar?

6. ¿Qué es más fácil para usted, que acepten o que rechacen?

7. ¿Por qué realiza el acto de invitar?

8. ¿Le parece que es necesario realizar invitaciones? ¿Por qué?

9. ¿Le parece que es cortés realizar una invitación? ¿Por qué?

10. ¿Le parece que es cortés rechazar una invitación? ¿Por qué?

11. ¿En qué situaciones podría ser cortés rechazar una invitación?

12. ¿Si la/lo invitan, se siente comprometido a devolver la invitación? 
13. ¿En qué situaciones invitaría por compromiso?

14. Si invita por compromiso, ¿qué prefiere, que acepten o que rechacen?

15. ¿En qué situaciones se espera que se hagan invitaciones?
16. ¿Cómo plantea una invitación?

17. ¿Hay una secuencia preparatoria?

18. Si la/lo invitan, ¿acepta inmediatamente o rechaza primero, y que insistan, y después acepta? 
